\title{
Spotlight on the Disc-Damage Likelihood Scale (DDLS)
}

\section{Kelvin KW Cheng Andrew J Tatham}

Princess Alexandra Eye Pavilion, Edinburgh, UK
Correspondence: Andrew J Tatham Princess Alexandra Eye Pavilion, Edinburgh, UK

Tel +44 I3। 5363753

Email andrewjtatham@gmail.com

\begin{abstract}
The disc damage likelihood scale (DDLS) is a tool for classifying glaucomatous structural changes to the optic disc based on the radial width of the neuroretinal rim at its thinnest location, or if no rim is present, the extent of absence of the rim. Unlike cup disc ratio (CDR), the DDLS also considers disc size. Twenty years after its first description, the aim of this review was to critically appraise evidence for the DDLS and evaluate its role in current practice. A literature search by two independent authors identified 33 relevant articles for inclusion. Five studies evaluated reproducibility, 5 diagnostic performance, and 2 studies examined ability to detect progression. Eleven studies evaluated correlation between DDLS and other markers of glaucoma. Despite the widespread availability of imaging devices such as optical coherence tomography (OCT), clinical examination of the optic disc remains an essential component of glaucoma diagnosis and monitoring. The DDLS provides a reliable method for semi-quantitative clinical grading of the optic disc in glaucoma, with higher reproducibility than methods such as CDR.
\end{abstract}

Keywords: glaucoma, cup-to-disc ratio, rim-to-disc ratio, disc damage likelihood scale

\section{Introduction}

According to the World Health Organization, glaucoma is the second leading cause of blindness worldwide, and thus a major public health issue. Globally, over 80 million people are estimated to be affected, ${ }^{1}$ a figure projected to increase to 114 million by $2040 .^{2}$ Glaucoma is a progressive optic neuropathy, defined by the presence of a characteristic pattern of damage to the optic nerve head $(\mathrm{ONH}){ }^{3}$ However, as there is large variation in normal ONH appearance, determining whether an optic nerve is healthy or damaged can be problematic, particularly in the early stages of disease. Furthermore, though damage to the optic nerve is associated with visual field loss, substantial optic nerve damage may occur before reproducible visual field loss is apparent. When detecting and monitoring glaucoma, it is thus essential to use information from structural and functional assessments, both to corroborate diagnosis, and monitor for changes over time.

Sophisticated imaging such as optical coherence tomography (OCT) has been introduced to provide objective, quantitative measures of the $\mathrm{ONH}$ and surrounding tissue. For example, OCT measurements of retinal nerve fiber layer (RNFL) thickness can be compared to a normative database and classified as outside, borderline or within normal limits. A limitation of imaging is that it may be affected by artefacts, including scan misalignment, segmentation errors, and artefacts induced by ocular co-morbidities, such as epiretinal membrane or posterior vitreous 
detachment. In addition, normative databases used by imaging devices exclude patients with high refractive error, including high myopes in whom there is a higher prevalence of glaucoma. Partly due to these limitations, real world studies examining the ability of imaging device normative databases to detect glaucoma have reported sensitivities and specificities of only around $80 \%{ }^{4}$ A further potential problem is that though availability of imaging devices is increasing, they have not been validated for use in community case finding settings and are not always available, especially in low-income countries, many of which have a high glaucoma prevalence. Furthermore, though imaging devices provide useful supplementary information to the clinical examination, they are currently recommended only as an adjunct test. For example, the recent 5 th edition of the European Glaucoma Society Guidelines states that though OCT can be useful for aiding diagnosis of glaucoma, the diagnosis cannot be made on the basis of OCT alone. ${ }^{5}$ Clinical examination of the $\mathrm{ONH}$ therefore remains an essential component of the glaucoma assessment.

In the 1960s Armaly described cup-to-disc ratio (CDR) as a method of semi-quantitative standardized assessment of the optic disc. CDR is still commonly used today, however, it has major limitations, especially as it does not take account of disc size or focal neuroretinal rim loss and has high inter- and intra-observer variability. As CDR is only measured along the vertical or horizontal meridians, it does not take account of focal neuroretinal rim loss occurring in other regions of the optic disc.

In 2002 Spaeth described the Disc Damage Likelihood Scale (DDLS), which measures the width and extent of the neuroretinal rim at its thinnest location, or if no rim is present, the extent of absence of the neuroretinal rim. The DDLS also considers the effect of disc size on the ratio between the neuroretinal rim and disc diameter. Twenty years after its introduction, the aim of this review was to critically appraise evidence for use of the DDLS and evaluate its role in current clinical practice.

\section{Method}

A search of PubMed was performed on 28th June 2021 using the search term (("disc damage likelihood scale") OR (DDLS)) OR ("disk damage likelihood scale"), searching across all fields for articles up to this date. This resulted in 166 articles, the titles and abstracts of which were reviewed by the two authors independently to identify those relevant to the DDLS in glaucoma, in the
English language. 33 articles were identified, of which 3 were review articles, 5 evaluated the performance of DDLS as a diagnostic tool, 11 evaluated correlation between DDLS and other structural and functional markers of glaucoma, 2 evaluated the ability of DDLS to detect glaucoma progression, and 5 evaluated the reproducibility of the DDLS. Other studies focused on topics including development of computer image analysis algorithms for automatic measurement of DDLS. A summary of studies is shown in Table 1.

\section{The Optic Nerve Head in Glaucoma}

The importance of being able to detect glaucomatous changes to the $\mathrm{ONH}$ was emphasised in the Ocular Hypertension Treatment Study (OHTS), which showed a higher proportion of patients developed $\mathrm{ONH}$ changes as the initial manifestation of glaucoma, compared to visual field endpoints. ${ }^{6}$ The neuroretinal rim has a honeycomb structure, reinforced with glial cells, in particular the processes of astrocytes. Unlike other conditions that cause optic atrophy in which hypertrophic gliosis is observed, in glaucoma, glial compensation for the lost axons fails. Therefore, cupping is observed in glaucoma and arteritic acute ischemic optic neuropathy, while flat and pale discs without cupping is more common with milder optic nerve head ischemia, such as non-arteritic acute ischemic optic neuropathy, or other retrolaminar/ retina-based optic nerve damage. ${ }^{7}$

The ratio between cup and disc depends to a large degree on optic disc size, with large variability in optic disc size observed between individuals, ranging from $0.80 \mathrm{~mm}^{2}$ to almost $6.00 \mathrm{~mm}^{2}$ in a Caucasian population. ${ }^{8}$ Optic disc size is also affected by refractive error and ethnicity.

Progressive optic disc changes noted on clinical examination, or on observation of stereoscopic photographs, have been proposed as the best reference standard for glaucoma diagnosis. ${ }^{9}$ The European Optic Disc Assessment Trial reported that ophthalmologists had a lower accuracy of classifying eyes as healthy or glaucomatous from stereoscopic photographs $(80.5 \%)^{10}$ compared to imaging devices, including Heidelberg Retina Tomograph (HRT) I (Heidelberg Engineering $\mathrm{GmbH}$, Heidelberg, Germany) (89.8\%) and GDx (GDx-variable corneal compensation (VCC) (Carl Zeiss Meditec AG, Jena, Germany) (92.3\%). There was also considerable variation in intra-observer agreement, with kappa ranging from -0.13 to 1.0 . Imaging devices have their own 
Table I Summary of Studies Examining the DDLS Identified in the Literature Search

\begin{tabular}{|c|c|c|}
\hline Authors & Year & Summary of Findings \\
\hline Buller, et $\mathrm{al}^{75}$ & 2021 & Evaluation of DDLS used by optometrists for monitoring patients in community shared care scheme. \\
\hline Bouacheria, et $\mathrm{al}^{76}$ & 2020 & Evaluation of computer image analysis algorithm enabling automatic measurement of DDLS. \\
\hline Formichella, et $\mathrm{al}^{74}$ & 2020 & $\begin{array}{l}\text { Significant correlation was reported between thinner OCT RNFL thickness and higher DDLS. Higher first visit } \\
\text { discharge rate found in patients with lower DDLS referred by community optometrists to glaucoma clinic. }\end{array}$ \\
\hline Kumar et $\mathrm{al}^{42}$ & 2019 & Evaluation of computer image analysis algorithm enabling automatic measurement of DDLS. \\
\hline Kara-José, et al ${ }^{37}$ & 2017 & $\begin{array}{l}\text { DDLS had good ability to differentiate between glaucomatous and healthy eyes, performing better than OCT RNFL } \\
\text { thickness and SAP MD. }\end{array}$ \\
\hline Lutaka, et $\mathrm{al}^{77}$ & 2017 & DDLS was significantly correlated with visual field index but less so with MD and PSD. \\
\hline Dervisevic et al ${ }^{78}$ & 2017 & DDLS was correlated with visual field loss. Tilted discs had significantly higher DDLS scores. \\
\hline Waisbourd et al ${ }^{69}$ & 2016 & $\begin{array}{l}\text { Evaluation of reproducibility of optic disc grading using photographs obtained by a hand-held fundus camera using } \\
\text { DDLS and CDR. }\end{array}$ \\
\hline Kitaoka et $\mathrm{al}^{71}$ & 2016 & $\begin{array}{l}\text { Evaluation of associations between the DDLS and various morphological parameters of the optic nerve head using } \\
\text { a stereo fundus camera. }\end{array}$ \\
\hline Zhang et $\mathrm{a}^{44}$ & 2016 & DDLS had the highest specificity for predicting a relative afferent pupillary defect (RAPD). \\
\hline Ekici et $\mathrm{al}^{45}$ & 2015 & $\begin{array}{l}\text { Structural measures including DDLS were not informative with regards to visual related performance or visual } \\
\text { related quality of life. }\end{array}$ \\
\hline Pahlitzsch et al ${ }^{4 !}$ & 2015 & DDLS was significantly correlated with HRT Moorfields Regression Analysis in preperimetric primary open angle glaucoma. \\
\hline Han et $\mathrm{al}^{72}$ & 2014 & DDLS obtained using 3D optic disc photography showed moderate agreement with that obtained by glaucoma specialists. \\
\hline Chandra et $\mathrm{al}^{79}$ & 2013 & Evaluation of correlation between CDR and DDLS with RNFL and global visual field indices. \\
\hline Ungar et $\mathrm{al}^{40}$ & 2012 & Evaluation of the ability of structural assessment of the disc including DDLS to predict glaucomatous visual field progression. \\
\hline Zangalli et $\mathrm{al}^{80}$ & 2011 & Review article of DDLS. \\
\hline Ichhpujani et al ${ }^{43}$ & 2011 & $\begin{array}{l}\text { Magnifier-assisted swinging flashlight method demonstrated as the most sensitive method of determining RAPD in } \\
\text { terms of differences in DDLS and visual field mean deviation. }\end{array}$ \\
\hline Majid et al ${ }^{39}$ & 2010 & Evaluation of the relationship between DDLS, visual field and OCT parameters for the diagnosis of glaucoma. \\
\hline Henderer et $\mathrm{al}^{38}$ & 2009 & $\begin{array}{l}\text { When using stereophotographs, DDLS had a higher sensitivity and specificity for detecting glaucomatous change } \\
\text { compared to vertical, horizontal, and maximal CDR. }\end{array}$ \\
\hline Bochmann et $\mathrm{al}^{29}$ & 2009 & Evaluation of the interobserver agreement for DDLS showing better agreement than for CDR. \\
\hline Hornova et $\mathrm{al}^{81}$ & 2008 & DDLS correlated well with visual field loss and topographical damage data obtained from HRT. \\
\hline Spaeth et $\mathrm{al}^{26}$ & 2006 & Review of known methods of grading optic disc glaucomatous changes including the DDLS. \\
\hline $\begin{array}{l}\text { Danesh-Meyer } \\
\text { et } \mathrm{al}^{36}\end{array}$ & 2006 & Evaluation of the relationship between the DDLS score and the global and sectoral optic disc (HRT) and VF parameters. \\
\hline $\begin{array}{l}\text { Danesh-Meyer } \\
\text { et } \text { al }^{16}\end{array}$ & 2006 & $\begin{array}{l}\text { Evaluation of the diagnostic strength of CDR, DDLS and HRT in patients with glaucoma, glaucoma suspects and } \\
\text { normal controls. }\end{array}$ \\
\hline Henderer et al ${ }^{82}$ & 2006 & DDLS editorial. \\
\hline Henderer et $\mathrm{al}^{28}$ & 2003 & $\begin{array}{l}\text { Evaluation of the reliability of DDLS versus CDR by determining inter- and intra-observer agreement of optic disc } \\
\text { stereophotographs and in vivo interobserver agreement of patient optic discs. }\end{array}$ \\
\hline Bayer et $\mathrm{a}^{30}$ & 2002 & DDLS strongly correlated with glaucomatous visual field damage. \\
\hline
\end{tabular}


Table I (Continued).

\begin{tabular}{|l|c|l|}
\hline Authors & Year & \multicolumn{1}{c|}{ Summary of Findings } \\
\hline Spaeth et a ${ }^{25}$ & 2002 & $\begin{array}{l}\text { Evaluation of the reproducibility of DDLS grading by comparing intra- and inter-observer reliability of DDLS versus } \\
\text { CDR. }\end{array}$ \\
\hline
\end{tabular}

Abbreviations: DDLS, disc damage likelihood scale; CDR, cup-to-disc ratio; OCT, optical coherence tomography; RNFL, retinal nerve fiber layer; SD-OCT, spectraldomain OCT; MD, mean deviation; PSD, pattern standard deviation; SAP, standard automated perimetry; RAPD, relative afferent pupillary defect; HRT, Heidelberg retinal tomograph.

limitations including 1) segmentation errors, 2) the limitations of normative databases, which tend to include mainly Caucasian patients and exclude eyes with moderate to high refractive errors, and 3) failure to demonstrate optic disc hemorrhages, an important indicator of increased risk of progression. OCT also struggles to classify unusual optic discs due to high myopia, tilted optic discs or peripapillary atrophy, the same eyes clinicians have difficulty classifying. A study of 2313 eyes scanned with Spectralis OCT RNFL reported $46 \%$ to have at least one image artefact which further impairs the reliability of OCT classification. $^{11}$ In addition, thinning of the RNFL is observed in other pathologies such as ischemic optic neuropathy, optic disc drusen, Parkinson's disease and Alzheimer's disease and therefore if used inappropriately can lead to incorrect diagnoses. ${ }^{12}$ Imaging devices can therefore supplement decision-making but direct observation of the optic nerve head remains an essential component of glaucoma assessment.

\section{Cup-to-Disc Ratio (CDR)}

Cup-to-disc ratio, which remains the most widely used method of quantifying disc changes in glaucoma, was first described in 1967 by Armaly. ${ }^{13}$ CDR is calculated by recording the cup diameter as a proportion of the total disc diameter, along either the horizontal or vertical planes. CDR has become widely used due to its simplicity, reasonable correlation with visual field loss, ${ }^{14,15}$ and wide advocation in many classical ophthalmological textbooks.

CDR, and especially the vertical CDR, allows easy quantification of optic disc appearance and communication between colleagues, however, CDR has only moderate reproducibility and has several serious limitations. Firstly, as CDR does not consider the size of optic disc, it is not unusual for healthy patients with large optic discs and normal visual fields to have a large CDR. Conversely, patients with small optic discs may develop glaucoma but have a small CDR. Second, as CDR is measured either vertically or horizontally, changes to the optic nerve head outside these regions may occur without any change in CDR. Therefore, unless change to the optic nerve head occurs at the poles, or is concentric, the vertical CDR will not capture these changes. ${ }^{16}$

The appreciation of cup size in relation to disc size is crucial given the wide variability in disc size ${ }^{17,18}$ and similar neuroretinal rim area ${ }^{19}$ among individuals. Therefore, in eyes with larger disc size, the area of the cup should be proportionally larger. ${ }^{20}$ A previous study reported that the optic nerve fiber count increased significantly with larger optic disc size. ${ }^{21}$ Given that CDR does not account for disc size, there is a significant overlap in CDR between normal and glaucomatous discs. ${ }^{22}$ CDR has also been reported to be the weakest parameter at distinguishing between normal and glaucomatous eyes compared to other quantifiable optic nerve, nerve fiber layer and visual field measurements. ${ }^{23}$

A previous study examining the relationship between vertical CDR and the estimated number of retinal ganglion cells found a non-linear relationship, indicating that in eyes with a large CDR, a large number of retinal ganglion cells would need to be lost for a small increase in CDR, providing further evidence that $\mathrm{CDR}$ is an insensitive method for evaluation of progressive neural losses in glaucoma. $^{24}$

\section{The Disc Damage Likelihood Scale (DDLS)}

The Disc Damage Likelihood Scale was first described by Spaeth in 2002. ${ }^{25}$ The DDLS is based on the radial width of the neuroretinal rim measured at its thinnest point, with the radial width of the rim compared to the diameter of the disc along the same axis. In effect, it is a measure of rim to disc ratio, rather than cup to disc ratio. Rim to disc ratio is an intuitive unit of measurement, particularly compared to $\mathrm{CDR}$, as it emphasizes the importance of examining rim tissue, rather than focusing on the area of absent tissue, the cup. When there is no rim tissue remaining, the rim/disc ratio is zero and the DDLS then measures the 
circumferential extent of rim tissue absence. The rim is defined as the width between the outer edge of the disc and the inner edge of the optic disc, which is the point at which the surface of the optic disc first dips posteriorly. ${ }^{26}$

The original description of the DDLS examined reproducibility of the DDLS compared to CDR when optic disc photographs were viewed by two glaucoma specialists using a stereoscopic viewer. To determine intra-observer agreement, each examiner graded the same batch of photographs three times on three different sessions. The DDLS was found to have superior intra- $(98 \%$ versus $85 \%)$ and inter-observer (85\% versus $74 \%$ ) reproducibility compared to $\mathrm{CDR}$.

Figure 1 summarizes DDLS staging system. There are 10 stages, extending from 1 to 10 , designed to provide enough granularity to identify change in the disc with progression of glaucoma but not so much detail to make utilization of the system difficult. For example, in average optic discs (1.5-2.0 $\mathrm{mm}$ diameter), eyes with a rim/disc ratio of 0.4 or more would be graded as DDLS stage 1, while eyes with rim/disc ratios of less than 0.1 would be graded as stage 5 or higher depending on the extent of absence of the rim. For example, a disc with absence of neuroretinal rim over less than 45-degrees would be graded as stage 6 , while absence of neuroretinal rim over more than 270-degrees would be graded as stage 10 . The calculated stage is increased by 1 when the optic disc is small (diameter $<1.5 \mathrm{~mm}$ ) and decreased by 1 when large (diameter $>2 \mathrm{~mm}$ ). Disc size measurements need to be corrected for any magnification induced by the lens used to examine the disc. Figure 2 illustrates real-life examples of DDLS grading for 3 eyes with small and large optic discs.

\section{Reliability of DDLS}

The reliability of the DDLS has been investigated. Henderer et al reported that the inter-observer and intraobserver agreement for the vertical DDLS measurement was greater than the vertical CDR when optic discs are assessed using optic disc photographs and inter-observer agreement was similar between the two methods for in vivo patient measurements. ${ }^{28}$ This was confirmed by Bochmann et al who reported that the inter-observer agreement for DDLS was greater than that for CDR (Cohen's kappa 0.902 vs 0.803$).{ }^{29}$ Bayer et $\mathrm{al}^{30}$ demonstrated a significant correlation between DDLS and MD ( $\mathrm{r}=$ -0.695, $p<0.001)$ and PSD $(r=0.703, p<0.001)$, significantly higher than previously recorded correlation severity of visual field loss and rim area ${ }^{31-33}$ or vertical $C D R .{ }^{34}$ Danesh-Mayer et al investigated the relationship between DDLS and global and regional functional loss on visual field testing. Visual fields were divided into 6 sectors based on the optic disc-visual field map as described by Garway-Heath et al. ${ }^{35}$ Sectoral MD was then calculated manually using the values of each point on total deviation plot of the HVF. DDLS was reported to have a strong correlation with global and all regional visual field mean deviation (MD) values. ${ }^{36}$ In this study, DDLS overestimated visual field damage in early glaucoma but underestimated visual field loss in advanced glaucoma, consistent with the known relationship between measurements of structural and functional changes in glaucoma, where structural changes tend to be detectable prior to changes that are detectable with conventional perimetry. Both Kara-Jose and Danesh-Mayer reported that DDLS was most strongly correlated with the inferotemporal rim area and that lowest correlation was with the nasal rim area. ${ }^{36,37}$ Hornová et al demonstrated that DDLS scores correlated well with structural measurements obtained using an HRT II device ( $r=0.923$ with Moorfields Regression Analysis and $\mathrm{r}=0.807$ with Cup Shape Measure Index) and with visual field loss indices (MD with $r=-0.792$; PSD $r=0.718$ ). The DDLS also has also been reported to have greater sensitivity and specificity of detecting glaucomatous changes over time compared to CDR using sequential stereo-photographs (DDLS vs vertical, horizontal and maximal CDR; sensitivity: $71.4 \%$ vs $63.9 \%, 66.7 \%$ and $47.2 \%$; specificity $70.9 \%$ vs $51.1 \%$, $40.4 \%$ and $48.9 \%)^{38}$

In addition, DDLS has been reported have good ability to discriminate various glaucoma cohorts, outperforming visual field indices (pattern standard deviation (PSD)), and average RNFL thickness measured by OCT. ${ }^{39}$ DDLS performed better at differentiating: 1) glaucoma versus glaucoma suspect and normal, 2) glaucoma versus normal only and 3) glaucoma and glaucoma suspect versus normal. In the analysis of glaucoma versus glaucoma suspect and normal eyes, DDLS achieved an area under the receiver operating characteristic curve (AUC) of 0.917, followed by corrected PSD (0.895), and OCT average RNFL thickness $(0.864){ }^{39}$ This echoes the report by Danesh-Meyer et al who reported DDLS had a greater AUC for detecting glaucoma (AUC $=0.91$ ) than CDR (0.81) and visual field PSD (0.80). ${ }^{16}$ Kara Jose et al also reported excellent discriminatory ability of DDLS, with an AUC of 0.92, though in this analysis vertical and horizontal CDR also 
A

\begin{tabular}{|c|c|c|c|c|c|c|}
\hline & \multicolumn{3}{|c|}{ Narrowest width of rim (rim/disc ratio) } & & Examples & \\
\hline DDLS Stage & $\begin{array}{l}\text { For small disc } \\
<1.50 \mathrm{~mm}\end{array}$ & $\begin{array}{l}\text { For medium } \\
\text { size disc } \\
1.50-2.00 \mathrm{~mm}\end{array}$ & $\begin{array}{l}\text { For large disc } \\
>2.00 \mathrm{~mm}\end{array}$ & $\begin{array}{l}1.25 \mathrm{~mm} \\
\text { optic nerve }\end{array}$ & $\begin{array}{c}1.75 \mathrm{~mm} \\
\text { optic nerve }\end{array}$ & $\begin{array}{c}2.25 \mathrm{~mm} \\
\text { optic nerve }\end{array}$ \\
\hline 1 & .5 & .4 or more & .3 or more & & & \\
\hline 2 & .4 to .49 & .3 to .39 & .2 to .29 & & & \\
\hline 3 & .3 to .39 & .2 to .29 & .1 to .19 & & & \\
\hline 4 & .2 to .29 & .1 to .19 & less than .1 & & & \\
\hline 5 & .1 to .19 & less than .1 & $\begin{array}{l}0 \text { for less than } \\
45^{\circ}\end{array}$ & & & \\
\hline 6 & less than .1 & $\begin{array}{l}0 \text { for less than } \\
45^{\circ}\end{array}$ & 0 for $46^{\circ}$ to $90^{\circ}$ & & & \\
\hline 7 & $\begin{array}{l}0 \text { for less than } \\
45^{\circ}\end{array}$ & 0 for $46^{\circ}$ to $90^{\circ}$ & $\begin{array}{c}0 \text { for } 91^{\circ} \text { to } \\
180^{\circ}\end{array}$ & & & \\
\hline 8 & 0 for $46^{\circ}$ to $90^{\circ}$ & $\begin{array}{c}0 \text { for } 91^{\circ} \text { to } \\
180^{\circ}\end{array}$ & $\begin{array}{c}\text { O for } 181^{\circ} \text { to } \\
270^{\circ}\end{array}$ & & & \\
\hline 9 & $\begin{array}{c}\text { of for } 91^{\circ} \text { to } \\
180^{\circ}\end{array}$ & $\begin{array}{c}\text { ofor } 181^{\circ} \text { to } \\
270^{\circ}\end{array}$ & $\begin{array}{c}0 \text { for more than } \\
270^{\circ}\end{array}$ & & & \\
\hline 10 & $\begin{array}{l}0 \text { for more than } \\
180^{\circ}\end{array}$ & $\begin{array}{l}0 \text { for more than } \\
270^{\circ}\end{array}$ & & & & \\
\hline
\end{tabular}

\section{B}

\begin{tabular}{|l|l|}
\hline Lens & Correction factor \\
\hline Volk 60D & $\times 0.88$ \\
\hline Volk 66D & $\times 1.0$ \\
\hline Volk 78D & $\times 1.2$ \\
\hline Volk 90D & $\times 1.33$ \\
\hline Nikon 60D & $\times 1.03$ \\
\hline Nikon 90D & $\times 1.63$ \\
\hline
\end{tabular}

Figure I (A) Spaeth's DDLS staging system stratified according to the optic disc sizes. Table reproduced from the Scottish Intercollegiate Guidelines Network (SIGN). Edinburgh: SIGN; 20I5. (SIGN publication no. 144). [cited March 20I5]. Available from URL: http://www.sign.ac.uk. These guidelines are licensed under the Creative Commons Attribution-Noncommercial-NoDerivatives 4.0 International Licence. ${ }^{27}$ (B) Table of magnification correction factors to accurately calculate disc size.

performed well, with AUCs of 0.94 and 0.91 respectively. ${ }^{35}$ The similar performance of DDLS and CDR in this study may have been due to CDR being measured at its longest diameter, not fixed at 90 and 180 degrees, meaning that the narrowest width of the neuroretinal rim was measured, similar to the DDLS.

Ungar et al reported that both higher vertical cup-todisc ratio and DDLS were predictive of glaucomatous 

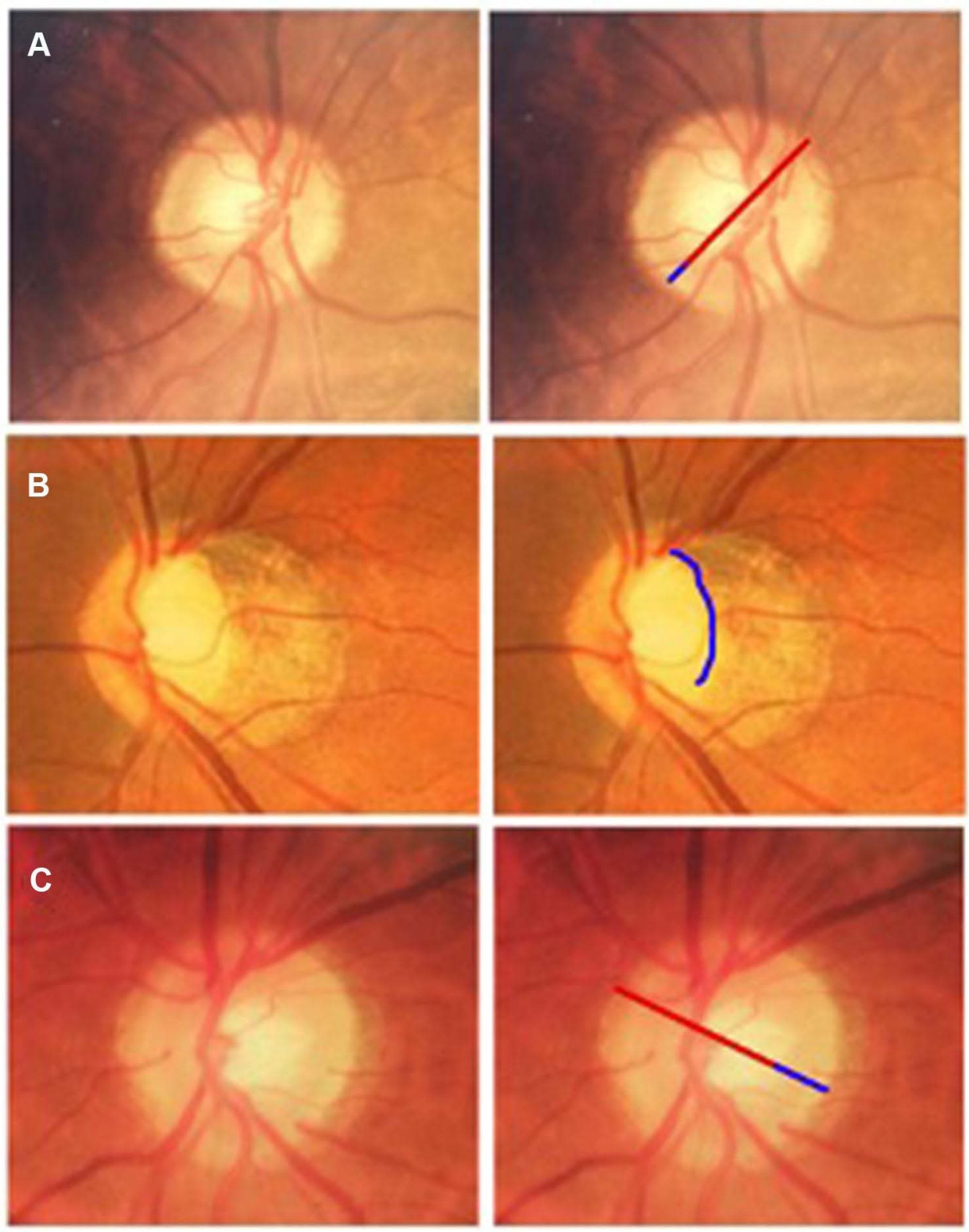

Figure 2 Examples of DDLS gradings for 3 eyes, with small $(\mathbf{A})$ and large (B and $\mathbf{C})$ optic disc diameters. For example (A), the thinnest width of the rim is approximately I/ 7 th $(0.14)$, the diameter of the optic disc in the same Meridian, which for a small optic disc, is equivalent to a DDLS of 3 . For example (B), there is no rim over approximately 130 degrees, which for a large optic disc, is equivalent to a DDLS of 6 . Care however must be taken in myopic eyes, to differentiate temporal sloping of the rim from absence of rim tissue. For example, (C), the thinnest width of the rim is approximately $1 / 4$ the diameter of the optic disc, which for a large disc is equivalent to a DDLS of 0 b.

visual field progression, with CDR having a higher odds ratio (3.2 vs 2.2-fold on Glaucoma Progression Analysis (GPA) and 2.2 vs 1.8-fold on VFI). However, the confidence ratios for DDLS were tighter supporting the greater intra- and intergrader reproducibility of DDLS compared to $\mathrm{CDR}^{40}$ A significant correlation between DDLS and HRT-GPA has also been reported in pre-perimetric glaucoma, reinforcing its utility in the early stages of disease. ${ }^{41}$

Kumar et al described a novel automated fundus image processing technique for glaucoma pre-screening comparing cup-to-disc and rim-to-disc ratio and reported greater sensitivity (0.97 vs 0.92$)$, specificity (0.97 vs 0.91$)$, and accuracy (0.97 vs 0.91$)$ of rim-disc based assessment compared to cup-to-disc-based assessment. ${ }^{42}$ Ichhpujani et al reported that a relative afferent pupillary defect (RAPD) was detected with a sensitivity of $84 \%$ when the difference in DDLS scores between the two eyes is greater than 2 using standard swinging flashlight test. ${ }^{43}$ Similarly, Zhang et al found that although IOP, DDLS, and MD asymmetries had similar sensitivities for identifying the 
presence of an RAPD $(0.49,0.47,0.56)$, DDLS had the greatest specificity of $0.86(0.73$ for IOP and 0.78 for $\mathrm{MD}){ }^{44}$

\section{Limitations of DDLS}

The DDLS is not without its limitations. Given its reliance on detection of the point of maximal focal change to the neuroretinal rim, it is not well suited for describing new areas of notching, as only the rim sector of greatest damage is used. In addition, it is less useful in eyes with atypical rims, for example highly myopic eyes or those with tilted discs. In addition, as structural changes from glaucoma occur along a continuum, categorizing eyes into one of ten groups introduces arbitrary boundaries. Grading using the DDLS also relies on the expertise of the observer, though the higher levels of inter-observer variability with DDLS compared to CDR, suggest that once trained in the technique, high levels of agreement can be obtained.

Similar to other structural measurements, DDLS is a surrogate for more patient-focused endpoints. There are very few studies examining the relationship between DDLS and patient-reported outcome measures. Ekici et al reported stronger correlation between quality-of-life measures and contrast sensitivity and visual field mean deviation, than with DDLS, however, the study included patients with a narrow range of DDLS scores and did not include any patients with DDLS scores of 9 or 10, those most likely to have impaired vision-related quality of life. $^{45}$

\section{Is DDLS Relevant Even in the World of Advanced Imaging Techniques?}

The availability of advanced imaging technologies such as OCT raises the question whether the DDLS has a role in modern glaucoma management. Though OCT imaging is useful in aiding detection and monitoring of glaucoma, there are several reasons why clinical examination of the optic nerve head remains essential. First, is its importance in excluding non-glaucomatous causes of optic neuropathy and other causes of visual field loss. Imaging such as OCT classifies eyes as normal, borderline or outside normal limits based on comparisons to normative databases, and although further diagnostic information can be gleaned from visualization of the raw scans, OCT alone does not provide a definitive diagnosis. ${ }^{4}$ Without clinical examination, important features such as disc pallor or optic disc hemorrhages are likely to be missed. Other important factors are artefact, and the limitations of imaging normative databases, which exclude eyes with high refractive error or ocular comorbidities, and which may not capture differences in ocular characteristics between people of different ethnicity. ${ }^{4}$ OCT measurements are also less useful in moderate to advanced disease due to the floor effect, below which RNFL measurements show no further decline, despite further glaucomatous neural loss. Though there is considerable variation between individuals, for average RNFL thickness, the floor can be reached in an eye with a visual field mean deviation of only $-15 \mathrm{~dB}$. The floor effect occurs primarily due to presence of residual tissue including blood vessels and glial cells. ${ }^{46,47}$

A large number of studies have examined the ability of imaging tests to detect glaucoma, ${ }^{48-56}$ summarized in a Cochrane Review. ${ }^{57}$ The review highlighted that the majority of studies used a case-control design which is likely to overestimate accuracy. To overcome this limitation, Bannister et al examined performance of imaging devices, including HRT, OCT and GDx-enhanced corneal compensation in a clinical setting. HRT MRA had highest sensitivity $(87 \%, 95 \%$ CI $80.2-92.1 \%)$ but lowest specificity $(63.9 \%, 95 \%$ CI $60.2-67.4 \%)$ whilst GDx had the lowest sensitivity $(35.1 \%, 95 \%$ CI $27.0-43.8 \%)$ but highest specificity $(97.2 \%, 95 \%$ CI $95.6-98.3 \%)$. The authors concluded that due to the imperfect results, automated imaging technologies are best utilized as adjuncts in glaucoma diagnosis and not relied on solely as a means of diagnosis as some patients with severe glaucoma may be missed. $^{58}$

The Bruch's membrane opening minimum rim width (BMO-MRW) is a relatively new metric which measures the minimum thickness of nerve tissue at the Bruch's membrane opening. ${ }^{59,60}$ Initial reports suggested that BMO-MRW is equivalent and potentially slightly superior compared to RNFL thickness ${ }^{59,61-63}$ for glaucoma detection. However, a recent study showed RNFL thickness $(\mathrm{AUC}=0.89)$ performed better than BMO-MRW $(\mathrm{AUC}=0.75)$ at identifying preperimetric glaucomatous optic nerve damage in eyes suspected of having glaucoma, whose final diagnosis was determined by observation for change over time. ${ }^{71}$ The poorer performance of BMO-MRW may have been due to a larger proportional decline in BMO-MRW with age, potentially leading to smaller differences in BMO-MRW between glaucomatous and healthy eyes in older populations. Alternatively, RNFL thickness may have performed better as eyes are often deemed to be suspicious of glaucoma 
based on appearance of the neuroretinal rim, rather than RNFL. In such circumstances, RNFL thickness is likely to provide additional complementary diagnostic information compared to BMO-MRW, which is a further measure of the rim. DDLS gradings and OCT measurements of RNFL thickness may be similarly complementary, assessing neuroretinal rim tissue and RNFL respectively. A further limitation of BMO-MRW is that it is affected by disc size, being thickest in small optic discs, it therefore does not account for optic disc size unlike DDLS. ${ }^{59,64}$

Unfortunately only a few studies have compared performance of the DDLS to imaging technologies (Table 1). Danesh-Meyer et al found the DDLS had superior ability than HRT-II to differentiate patients with glaucoma and suspected glaucoma from healthy controls, with an AUC of 0.95 compared to only 0.68 for the HRT-II Moorfields regression analysis ${ }^{16}$ and 0.84 for CDR. Suggested explanations for a stronger correlation between DDLS and visual field loss compared to HRT and visual field loss included the inclusion of blood vessels within the neuroretinal rim in HRT and that HRT does not consider disc variations including disc tilting, peripapillary color variation and disc size. ${ }^{36}$ A study comparing DDLS scores to OCT reported strong positive correlation between CDR measured using OCT $(r=0.657, p<0.001)$, and strong inverse correlation with the average $(\mathrm{r}=-0.620$, $\mathrm{p}<0.001)$ and inferior $(\mathrm{r}=-0.620, \mathrm{p}<0.001)$ RNFL thickness, ${ }^{37}$ however a difficulty of comparing diagnostic ability of different structural tests is the choice of reference standard, which should be independent of the tests evaluated.

Further limitations of imaging devices include the frequent introduction of new technology, potentially leading to loss of backward compatibility and obsolescence. ${ }^{65}$ Reports have also shown the lack of interchangeability of data between devices, ${ }^{66,67}$ and imaging devices remain unavailable in many settings, such as primary care or lowincome countries. Due to the limitations of imaging devices, the DDLS clearly remains a valuable tool.

\section{Optic Disc Photography and Clinical Examination}

Optic disc photography was the original imaging modality, providing a means to capture baseline optic disc images, and through serial imaging, observe for progressive changes over time. Photography also provided an excellent method of capturing optic disc hemorrhages, an important risk factor for progression. However, photographs are limited due to the difficulty of accurate assessment of disc size and due to variable image quality. ${ }^{25,28,65}$ Interpretation of optic disc appearance also depends on expertise of the observer, with evidence that agreement between observers in identifying optic disc changes from stereophotographs is only slight to fair. ${ }^{68}$

A potential advantage of the DDLS is that it forces the grader to observe for specific features, which may improve reproducibility of the assessment compared to unstructured optic disc grading. Few studies have evaluated this, however, Waisbourd et al investigated the utility of nonmydriatic monoscopic disc photographs for diagnosing glaucoma and demonstrated that the intra-observer and inter-observer agreement between optic disc grading using monoscopic disc photographs and optic disc biomicroscopy was only moderate, both for CDR (0.71 and 0.69 interclass correlations) and DDLS (0.65 and 0.67 interclass correlations). ${ }^{69}$ The results from this study demonstrate weaker intra-observer and inter-observer agreement compared to previous studies, perhaps due to poorer image quality - monoscopic images do not allow 3D evaluation of discs and undilated pupils affect illumination of the disc and therefore picture quality, impairing picture grading. The assessment of optic discs using monoscopic disc photographs relies on the course of small vessels and shadowing of adjacent structures and therefore is more susceptible to subjective findings. ${ }^{70}$ This is in contrast to stereoscopic images which allow direct visualization of depth.

In the Glaucoma Stereo Analysis Study, a semiautomated analysis of stereophotographs of the optic nerve head where an investigator marked the contour lines in stereophotographs was used to measure DDLS. In agreement with other studies, this method showed a correlation between DDLS and MD $(r=-0.267, p=$ $0.001)$, PSD $(\mathrm{r}=0.233, \mathrm{p}=0.001)$ and $\operatorname{CDR}(\mathrm{r}=0.381$, $\mathrm{p}=0.001){ }^{71}$ It is unclear if the poorer correlations reported here is due to the use of stereophotographs using a prototype analysis software. Good agreement (weighted kappa value $0.59 \pm 0.003$ ) between DDLS stages obtained by stereophotographs using the prototype software and by a glaucoma specialist was reported previously. ${ }^{72}$ This study also included patients with myopic glaucomatous discs defined as tilted appearing discs with temporal crescent peripapillary atrophy $(n=96,51.3 \%)$, in which 
measurement of the DDLS may not be accurate as the rim may not be as distinct.

\section{Use of DDLS in Primary Care}

The DDLS has been recommended for use in glaucoma case finding schemes and referral guidelines. For example, the Scottish Intercollegiate Guidelines Network (SIGN) glaucoma guidelines recommend that information regarding DDLS is included in all referrals from community optometry to hospital glaucoma clinics. ${ }^{27}$ The aim was to reduce the number of false positives among patients referred for specialist assessment, while also minimizsing the risk of patients with glaucomatous optic disc changes being missed. Though the guidelines also made other recommendations and led to the provision of pachymeters to community optometrists across Scotland, an evaluation of false positive referral rates found a $33.5 \%$ reduction in the proportion of patients discharged at their first visit to the glaucoma clinic following introduction of the guideline. ${ }^{73}$ Though this suggests improved accuracy of case finding when the DDLS is used, the study did not examine characteristics of individuals not referred to the hospital eye service, meaning the effect of the guidelines on false negative referrals is not known. However, a further study of glaucoma referrals in Scotland found the first visit discharge rate was lower in patients with higher DDLS scores, decreasing from $50 \%$ in those with a DDLS of 3 , to $0 \%$ in those with a DDLS $\geq 6$. $^{74}$ No patients with a DDLS of less than 4 were diagnosed with glaucoma at their first visit. This study though was limited by the small number of patients in which DDLS had been recorded. Despite DDLS being stipulated as essential information to include in referrals, only 65 of $618(10.5 \%)$ consecutive referrals to the glaucoma clinic included DDLS information, suggesting a lack of awareness of the value of DDLS among community optometrists who have a front-line role in opportunistic glaucoma case detection in the UK.

\section{Conclusion}

Evidence suggests that the DDLS is a more accurate and reliable method of detecting glaucoma and monitoring glaucomatous disc changes compared to the CDR. The DDLS provides enough granularity to allow early changes in the optic disc to be identified in a method that is easy to understand and apply with minimal training. Advanced imaging solutions allow objective recording of disc changes and several studies have shown good correlation with DDLS. However, imaging methods such as OCT are limited by potential future obsolescence and high cost. Further limitations mean that although imaging solutions can help supplement the clinician in identifying and monitoring glaucoma, they cannot yet replace clinical examination. Optic disc and retinal nerve fiber examination remains an essential component of glaucoma diagnosis and monitoring, with the DDLS providing a reproducible method for categorizing structural changes from glaucoma. Despite the increasing use of imaging devices, the DDLS remains a useful method of documenting the glaucomatous optic nerve head.

\section{Disclosure}

Dr Andrew J Tatham

Consultant/Advisor (C) - Allergan, Santen, Théa, Glaukos

Lecture Fees - Allergan, Santen, Heidelberg Engineering, Glaukos, Novartis

Grant Support - Allergan, Novartis. The authors report no other conflicts of interest in this work.

\section{References}

1. Quigley HA, Broman AT. The number of people with glaucoma worldwide in 2010 and 2020. Br J Ophthalmol. 2006;90 (3):262-267. doi:10.1136/bjo.2005.081224

2. Tham Y-C, Li X, Wong TY, Quigley HA, Aung T, Cheng C-Y. Global prevalence of glaucoma and projections of glaucoma burden through 2040: a systematic review and meta-analysis. Ophthalmology. 2014;121(11):2081-2090. doi:10.1016/j.ophtha.2014.05.013

3. Foster PJ, Buhrmann R, Quigley HA, Johnson GJ. The definition and classification of glaucoma in prevalence surveys. $\mathrm{Br} J$ Ophthalmol. 2002;86(2):238-242. doi:10.1136/bjo.86.2.238

4. Azuara-Blanco A, Banister K, Boachie C, et al. Automated imaging technologies for the diagnosis of glaucoma: a comparative diagnostic study for the evaluation of the diagnostic accuracy, performance as triage tests and cost-effectiveness (GATE study). Health Technol Assess. 2016;20(8):1-168. doi:10.3310/hta20080

5. European Glaucoma Society. Terminology and Guidelines for Glaucoma. 5th ed. 2020.

6. Kass MA, Heuer DK, Higginbotham EJ, et al. The ocular hypertension treatment study: a randomized trial determines that topical ocular hypotensive medication delays or prevents the onset of primary open-angle glaucoma. Arch Ophthalmol. 2002;120(6):701-13; discussion 829-830.

7. Lee EJ, Han JC, Park DY, Kee C. A neuroglia-based interpretation of glaucomatous neuroretinal rim thinning in the optic nerve head. Prog Retin Eye Res. 2020;77:100840.

8. Jonas JB, Budde WM. Diagnosis and pathogenesis of glaucomatous optic neuropathy: morphological aspects. Prog Retin Eye Res. 2000;19(1):1-40. doi:10.1016/S1350-9462(99)00002-6

9. Medeiros FA, Zangwill LM, Bowd C, Sample PA, Weinreb RN. Use of progressive glaucomatous optic disk change as the reference standard for evaluation of diagnostic tests in glaucoma. $\mathrm{Am}$ J Ophthalmol. 2005;139(6):1010-1018. doi:10.1016/j.ajo.2005.01. 003

10. Reus NJ, Lemij HG, Garway-Heath DF, et al. Clinical assessment of stereoscopic optic disc photographs for glaucoma: the European optic disc assessment trial. Ophthalmology. 2010;117(4):717-723. doi:10. 1016/j.ophtha.2009.09.026 
11. Liu Y, Simavli H, Que CJ, et al. Patient characteristics associated with artifacts in spectralis optical coherence tomography imaging of the retinal nerve fiber layer in glaucoma. Am J Ophthalmol. 2015;159 (3):565-76.e2. doi:10.1016/j.ajo.2014.12.006

12. Pasol J. Neuro-ophthalmic disease and optical coherence tomography: glaucoma look-alikes. Curr Opin Ophthalmol. 2011;22 (2):124-132. doi:10.1097/ICU.0b013e328343c1a3

13. Armaly MF. Genetic determination of cup/disc ratio of the optic nerve. Arch Ophthalmol. 1967;78(1):35-43. doi:10.1001/archopht 1967.00980030037007

14. Douglas GR, Drance SM, Schulzer M. A correlation of fields and discs in open angle glaucoma. Can J Ophthalmol. 1974;9(4):391-398.

15. Hart WM, Yablonski M, Kass MA, Becker B. Multivariate analysis of the risk of glaucomatous visual field loss. Arch Ophthalmol. 1979;97(8):1455-1458. doi:10.1001/archopht.1979.01020020117005

16. Danesh-Meyer HV, Gaskin BJ, Jayusundera T, Donaldson M, Gamble GD. Comparison of disc damage likelihood scale, cup to disc ratio, and Heidelberg retina tomograph in the diagnosis of glaucoma. $\mathrm{Br}$ J Ophthalmol. 2006;90(4):437-441. doi:10.1136/bjo.2005.077131

17. Jonas JB, Budde WM, Panda-Jonas S. Ophthalmoscopic evaluation of the optic nerve head. Surv Ophthalmol. 1999;43(4):293-320.

18. Hoffmann EM, Zangwill LM, Crowston JG, Weinreb RN. Optic disk size and glaucoma. Surv Ophthalmol. 2007;52(1):32-49. doi:10.1016/j.survophthal.2006.10.002

19. Tsai CS, Zangwill L, Gonzalez C, et al. Ethnic differences in optic nerve head topography. $J$ Glaucoma. 1995;4(4):248-257. doi:10.1097/00061198-199508000-00006

20. Budde WM, Jonas JB, Martus P, Gründler AE. Influence of optic disc size on neuroretinal rim shape in healthy eyes. J Glaucoma. 2000;9 (5):357-362. doi:10.1097/00061198-200010000-00003

21. Jonas JB, Schmidt AM, Müller-Bergh JA, Schlötzer-Schrehardt UM, Naumann GO. Human optic nerve fiber count and optic disc size. Invest Ophthalmol Vis Sci. 1992;33(6):2012-2018.

22. Caprioli J, Miller JM. Videographic measurements of optic nerve topography in glaucoma. Invest Ophthalmol Vis Sci. 1988;29 (8):1294-1298.

23. Caprioli J. Discrimination between normal and glaucomatous eyes. Invest Ophthalmol Vis Sci. 1992;33(1):153-159.

24. Tatham AJ, Weinreb RN, Zangwill LM, Liebmann JM, Girkin CA, Medeiros FA. The relationship between cup-to-disc ratio and estimated number of retinal ganglion cells. Invest Ophthalmol Vis Sci. 2013;54(5):3205-3214. doi:10.1167/iovs.12-11467

25. Spaeth GL, Henderer J, Liu C, et al. The disc damage likelihood scale: reproducibility of a new method of estimating the amount of optic nerve damage caused by glaucoma. Trans Am Ophthalmol Soc. 2002;100:181-5; discussion 185-186.

26. Spaeth GL, Lopes JF, Junk AK, Grigorian AP, Henderer J. Systems for staging the amount of optic nerve damage in glaucoma: a critical review and new material. Surv Ophthalmol. 2006;51(4):293-315. doi:10.1016/j.survophthal.2006.04.008

27. Scottish Intercollegiate Guidelines Network (SIGN). Glaucoma referral and safe discharge: a national clinical guideline [Internet] Edinburgh: SIGN; 2015. Available from: https://www.sign.ac.uk/. Accessed September 18, 2021.

28. Henderer JD, Liu C, Kesen M, et al. Reliability of the disk damage likelihood scale. Am J Ophthalmol. 2003;135(1):44-48. doi:10.1016/ S0002-9394(02)01833-0

29. Bochmann F, Howell JP, Meier C, Becht C, Thiel MA. The disc damage likelihood scale (DDLS): interobserver agreement of a new grading system to assess glaucomatous optic disc damage. Klin Monatsbl Augenheilkd. 2009;226(4):280-283. doi:10.1055/s-0028-1109288

30. Bayer A, Harasymowycz P, Henderer JD, Steinmann WG, Spaeth GL. Validity of a new disk grading scale for estimating glaucomatous damage: correlation with visual field damage. $\mathrm{Am}$ $J$ Ophthalmol. 2002;133(6):758-763. doi:10.1016/S0002-9394(02) 01422-8
31. Lee KH, Park KH, Kim DM, Youn DH. Relationship between optic nerve head parameters of Heidelberg Retina Tomograph and visual field defects in primary open-angle glaucoma. Korean J Ophthalmol. 1996;10(1):24-28. doi:10.3341/kjo.1996.10.1.24

32. Iester M, Mikelberg FS, Courtright P, Drance SM. Correlation between the visual field indices and Heidelberg retina tomograph parameters. J Glaucoma. 1997;6(2):78-82. doi:10.1097/00061198199704000-00002

33. Caprioli J, Miller JM. Correlation of structure and function in glaucoma. Quantitative measurements of disc and field. Ophthalmology. 1988;95(6):723-727. doi:10.1016/S0161-6420(88)33116-7

34. Gloster J. Quantitative relationship between cupping of the optic disc and visual field loss in chronic simple glaucoma. Br J Ophthalmol. 1978;62(10):665-669. doi:10.1136/bjo.62.10.665

35. Garway-Heath DF, Poinoosawmy D, Fitzke FW, Hitchings RA. Mapping the visual field to the optic disc in normal tension glaucoma eyes. Ophthalmology. 2000;107(10):1809-1815. doi:10.1016/S01616420(00)00284-0

36. Danesh-Meyer HV, Ku JYF, Papchenko TL, Jayasundera T, Hsiang JC, Gamble GD. Regional correlation of structure and function in glaucoma, using the disc damage likelihood scale, Heidelberg Retina Tomograph, and visual fields. Ophthalmology. 2006;113 (4):603-611. doi:10.1016/j.ophtha.2005.10.055

37. Kara-José AC, Melo LASJ, Esporcatte BLB, Endo ATNH, Leite MT, Tavares IM. The disc damage likelihood scale: diagnostic accuracy and correlations with cup-to-disc ratio, structural tests and standard automated perimetry. PLoS One. 2017;12(7):e0181428. doi:10.1371/ journal.pone.0181428

38. Henderer J, Wang Y, Bayer A, Altangerel U, Schwartz L, Schmidt C. Evaluating a new disc staging scale for glaucomatous damage: the ability to detect change over time. Eur J Ophthalmol. 2009;19 (3):404-410. doi:10.1177/112067210901900313

39. Abdul Majid ASB, Kwag JH, Jung SH, Yim HB, Kim YD, Kang KD. Correlation between disc damage likelihood scale and optical coherence tomography in the diagnosis of glaucoma. Ophthalmol J Int. 2010;224(5):274-282.

40. Ungar AK, Wollstein G, Ishikawa H, et al. Evaluating objective and subjective quantitative parameters at the initial visit to predict future glaucomatous visual field progression. Ophthalmic Surg Lasers Imaging. 2012;43(5):416-424. doi:10.3928/15428877-20120524-01

41. Pahlitzsch M, Torun N, Erb C, et al. Significance of the disc damage likelihood scale objectively measured by a non-mydriatic fundus camera in preperimetric glaucoma. Clin Ophthalmol. 2015;9: 2147-2158. doi:10.2147/OPTH.S93213

42. Kumar JRH, Seelamantula CS, Kamath YS, Jampala R. Rim-to-disc ratio outperforms cup-to-disc ratio for glaucoma prescreening. Sci Rep. 2019;9(1):7099. doi:10.1038/s41598-019-43385-2

43. Ichhpujani P, Rome JE, Jindal A, et al. Comparative study of 3 techniques to detect a relative afferent pupillary defect. J Glaucoma. 2011;20 (9):535-539. doi:10.1097/IJG.0b013e3181f464e8

44. Zhang AY, Lu L, Ali M, et al. Disc-Damage Likelihood Scale (DDLS) as a clinical indicator of the presence of a Relative Afferent Pupillary Defect (RAPD). J Glaucoma. 2016;25(10):e9106. doi:10.1097/IJG.0000000000000425

45. Ekici F, Loh R, Waisbourd M, et al. Relationships between measures of the ability to perform vision-related activities, vision-related quality of life, and clinical findings in patients with glaucoma. JAMA Ophthalmol. 2015;133(12):1377-1385. doi:10.1001/jamaophthalmol. 2015.3426

46. Radius RL, Anderson DR. The histology of retinal nerve fiber layer bundles and bundle defects. Arch Ophthalmol. 1979;97(5):948-950. doi:10.1001/archopht.1979.01020010506027

47. Ye C, Yu M, Leung CK-S. Impact of segmentation errors and retinal blood vessels on retinal nerve fibre layer measurements using spectral-domain optical coherence tomography. Acta Ophthalmol (Copenh). 2016;94(3):e211-219. doi:10.1111/aos.12762 
48. Ferreras A, Pablo LE, Pajarín AB, Larrosa JM, Polo V, Pueyo V. Diagnostic ability of the Heidelberg retina tomograph 3 for glaucoma. Am J Ophthalmol. 2008;145(2):354-359. doi:10.1016/j.ajo.2007.09.039

49. Reus NJ, Lemij HG. Diagnostic accuracy of the GDx VCC for glaucoma. Ophthalmology. 2004;111(10):1860-1865. doi:10.1016/j. ophtha.2004.04.024

50. Wu H, de Boer JF, Chen TC. Diagnostic capability of spectral-domain optical coherence tomography for glaucoma. Am J Ophthalmol. 2012;153 (5):815-826.e2. doi:10.1016/j.ajo.2011.09.032

51. Akashi A, Kanamori A, Nakamura M, Fujihara M, Yamada Y, Negi A. Comparative assessment for the ability of Cirrus, RTVue, and 3D-OCT to diagnose glaucoma. Invest Ophthalmol Vis Sci. 2013;54(7):4478-4484. doi:10.1167/iovs.12-11268

52. Oddone F, Centofanti M, Tanga L, et al. Influence of disc size on optic nerve head versus retinal nerve fiber layer assessment for diagnosing glaucoma. Ophthalmology. 2011;118(7):1340-1347.

53. Medeiros FA, Zangwill LM, Bowd C, Weinreb RN. Comparison of the GDx VCC scanning laser polarimeter, HRT II confocal scanning laser ophthalmoscope, and stratus OCT optical coherence tomograph for the detection of glaucoma. Arch Ophthalmol. 2004;122 (6):827-837. doi:10.1001/archopht.122.6.827

54. Mwanza J-C, Durbin MK, Budenz DL, et al. Glaucoma diagnostic accuracy of ganglion cell-inner plexiform layer thickness: comparison with nerve fiber layer and optic nerve head. Ophthalmology. 2012;119(6):1151-1158. doi:10.1016/j.ophtha.2011.12.014

55. De León-ortega JE, Sakata LM, Monheit BE, McGwin G, Arthur SN, Girkin CA. Comparison of diagnostic accuracy of Heidelberg retina tomograph II and Heidelberg retina tomograph 3 to discriminate glaucomatous and nonglaucomatous eyes. Am $J$ Ophthalmol. 2007;144(4):525-532. doi:10.1016/j.ajo.2007.06.021

56. Badalà F, Nouri-Mahdavi K, Raoof DA, Leeprechanon N, Law SK, Caprioli J. Optic disk and nerve fiber layer imaging to detect glaucoma. Am J Ophthalmol. 2007;144(5):724-732. doi:10.1016/j.ajo.2007.07.010

57. Michelessi M, Lucenteforte E, Oddone F, et al. Optic nerve head and fibre layer imaging for diagnosing glaucoma. Cochrane Database Syst Rev. 2015;30(11):CD008803.

58. Banister K, Boachie C, Bourne R, et al. Can automated imaging for optic disc and retinal nerve fiber layer analysis aid glaucoma detection? Ophthalmology. 2016;123(5):930-938. doi:10.1016/j. ophtha.2016.01.041

59. Chauhan BC, O'Leary N, AlMobarak FA, et al. Enhanced detection of open-angle glaucoma with an anatomically accurate optical coherence tomography-derived neuroretinal rim parameter. Ophthalmology. 2013;120(3):535-543. doi:10.1016/j.ophtha.2012.09.055

60. Reis ASC, O'Leary N, Yang H, et al. Influence of clinically invisible, but optical coherence tomography detected, optic disc margin anatomy on neuroretinal rim evaluation. Invest Ophthalmol Vis Sci. 2012;53(4):1852-1860. doi:10.1167/iovs.11-9309

61. Danthurebandara VM, Vianna JR, Sharpe GP, et al. Diagnostic accuracy of glaucoma with sector-based and a new total profile-based analysis of neuroretinal rim and retinal nerve fiber layer thickness. Invest Ophthalmol Vis Sci. 2016;57(1):181-187. doi:10.1167/iovs.1517820

62. Malik R, Belliveau AC, Sharpe GP, Shuba LM, Chauhan BC, Nicolela MT. Diagnostic accuracy of optical coherence tomography and scanning laser tomography for identifying glaucoma in myopic eyes. Ophthalmology. 2016;123(6):1181-1189. doi:10.1016/j.ophtha. 2016.01.052

63. Enders P, Adler W, Kiessling D, et al. Evaluation of two-dimensional Bruch's membrane opening minimum rim area for glaucoma diagnostics in a large patient cohort. Acta Ophthalmol (Copenh). 2019;97 (1):60-67. doi:10.1111/aos.13698

64. Chauhan BC, Danthurebandara VM, Sharpe GP, et al. Bruch's membrane opening minimum rim width and retinal nerve fiber layer thickness in a normal white population: a multicenter study. Ophthalmology. 2015;122 (9):1786-1794. doi:10.1016/j.ophtha.2015.06.001
65. Spaeth GL, Reddy SC. Imaging of the optic disk in caring for patients with glaucoma: ophthalmoscopy and photography remain the gold standard. Surv Ophthalmol. 2014;59(4):454-458. doi:10.1016/j. survophthal.2013.10.004

66. Leite MT, Rao HL, Weinreb RN, et al. Agreement among spectral-domain optical coherence tomography instruments for assessing retinal nerve fiber layer thickness. Am J Ophthalmol. 2011;151 (1):85-92.e1. doi:10.1016/j.ajo.2010.06.041

67. Moreno-Montañés J, Antón A, García N, Olmo N, Morilla A, Fallon M. Comparison of retinal nerve fiber layer thickness values using stratus optical coherence tomography and Heidelberg retina tomograph-III. J Glaucoma. 2009;18(7):528-534. doi:10.1097/ IJG.0b013e318193c29f

68. Jampel HD, Friedman D, Quigley H, et al. Agreement among glaucoma specialists in assessing progressive disc changes from photographs in open-angle glaucoma patients. Am J Ophthalmol. 2009;147 (1):39-44.e1. doi:10.1016/j.ajo.2008.07.023

69. Waisbourd M, Bond EA, Sullivan T, et al. Evaluation of nonmydriatic hand-held optic disc photography grading in the Philadelphia glaucoma detection and treatment project. J Glaucoma. 2016;25(5): e520-525. doi:10.1097/IJG.0000000000000382

70. Choi YR, Lee SH. Optic disc measurements with stereophotograph in normal eyes. J Korean Ophthalmol Soc. 1999;40(12):3437-3445.

71. Kitaoka Y, Tanito M, Yokoyama Y, et al. Estimation of the disc damage likelihood scale in primary open-angle glaucoma: the glaucoma stereo analysis study. Graefes Arch Clin Exp Ophthalmol. 2016;254(3):523-528. doi:10.1007/s00417-015-3239-0

72. Han JW, Cho SY, Kang KD. Correlation between optic nerve parameters obtained using 3D nonmydriatic retinal camera and optical coherence tomography: interobserver agreement on the disc damage likelihood scale. J Ophthalmol. 2014;2014:931738. doi:10.1155/ 2014/931738

73. Sii S, Nasser A, Loo CY, Croghan C, Rotchford A, Agarwal PK. The impact of SIGN glaucoma guidelines on false-positive referrals from community optometrists in Central Scotland. $\mathrm{Br} J$ Ophthalmol. 2019;103(3):369-373. doi:10.1136/bjophthalmol-2017-311429

74. Formichella P, Annoh R, Zeri F, Tatham AJ. The role of the disc damage likelihood scale in glaucoma detection by community optometrists. Ophthalmic Physiol Opt. 2020;40(6):752-759. doi:10. 1111/opo.12734

75. Buller AJ. Results of a glaucoma shared care model using the enhanced glaucoma staging system and disc damage likelihood scale with a novel scoring scheme in New Zealand. Clin Ophthalmol. 2021;15:57-63. doi:10.2147/OPTH.S285966

76. Bouacheria M, Cherfa Y, Cherfa A, Belkhamsa N. Automatic glaucoma screening using optic nerve head measurements and random forest classifier on fundus images. Phys Eng Sci Med. 2020;43 (4):1265-1277. doi:10.1007/s13246-020-00930-y

77. Iutaka NA, Grochowski RA, Kasahara N. Correlation between visual field index and other functional and structural measures in glaucoma patients and suspects. J Ophthalmic Vis Res. 2017;12(1):53-57. doi:10.4103/jovr.jovr_98_16

78. Dervisevic E, Pavljasevic S, Dervisevic A, Kasumovic SS. Challenges in early glaucoma detection. Med Arch. 2016;70(3):203-207.

79. Chandra A, Bandyopadhyay AK, Bhaduri G. A comparative study of two methods of optic disc evaluation in patients of glaucoma. Oman J Ophthalmol. 2013;6(2):103-107. doi:10.4103/0974-620X.116643

80. Zangalli C, Gupta SR, Spaeth GL. The disc as the basis of treatment for glaucoma. Saudi J Ophthalmol. 2011;25(4):381-387. doi:10. 1016/j.sjopt.2011.07.003

81. Hornova J, Jbv KN, Prasad A, Freitas DGJ, Nunes CM. Correlation of disc damage likelihood scale, visual field, and Heidelberg retina tomograph II in patients with glaucoma. Eur J Ophthalmol. 2008;18 (5):739-747. doi:10.1177/112067210801800513

82. Henderer JD. Disc damage likelihood scale. $\mathrm{Br} J$ Ophthalmol. 2006;90(4):395-396. doi:10.1136/bjo.2005.083360 


\section{Publish your work in this journal}

Clinical Ophthalmology is an international, peer-reviewed journal covering all subspecialties within ophthalmology. Key topics include: Optometry; Visual science; Pharmacology and drug therapy in eye diseases; Basic Sciences; Primary and Secondary eye care; Patient Safety and Quality of Care Improvements. This journal is indexed on PubMed

Submit your manuscript here: https://www.dovepress.com/clinical-ophthalmology-journal
Central and CAS, and is the official journal of The Society of Clinical Ophthalmology (SCO). The manuscript management system is completely online and includes a very quick and fair peer-review system, which is all easy to use. Visit http://www.dovepress.com/ testimonials.php to read real quotes from published authors. 